\title{
WILL FISH DISAPPEAR BY 2048?
}

\author{
Wanwan Kurniawan ${ }^{1 *}$ \\ ${ }^{1}$ Research Center for Oceanography, Indonesian Institute of Sciences \\ Jl. Pasir Putih I, Ancol Timur, Jakarta Utara 14430 \\ *Email address: wanwan.kurniawan@ @ipi.go.id
}

\begin{abstract}
In 2006, a tumult arose in the world of fisheries. A controversial paper titled "Impacts of biodiversity loss on ocean ecosystem services" by Worm et al. (2006) was published in Science. The paper was sensational since it alluded to a prediction that global populations of marine fish (finfish and invertebrates) will be $100 \%$ collapsed by 2048 . The paper was authored by a group of marine ecologists and economists in which Boris Worm from Dalhousie University Canada led the authorship. After the paper was published, the issue of fish disappearance in 2048 became hot topics in the world's mass media. In fact, the Worm et al. paper triggered the debates among researchers. Over time the debates heated up. Surprisingly, a reconciliation took place in 2009, marked by a collaboration between Worm's team and his critics, writing another paper in Science. The present essay reaffirms the invalidity of the global collapse prediction in 2048 as revealed by many researchers. It is also shown that the Worm et al. paper did not really state that all fish will disappear and through the joint paper in 2009, Worm and colleagues have indirectly rectified the prediction already.
\end{abstract}

Keywords: controversial paper, fish disappearance in 2048, global population.

\section{INTRODUCTION}

In the realm of fisheries, there are two diverging views on the status and future of global fisheries. One view comes from marine ecologists or conservationists who perceive that fish populations are globally overexploited and current exploitation rates drive populations to be continually declining. Another view comes from fisheries scientists who perceive populations are not globally overexploited and no trend of decline in global fisheries (Hilborn, 2007a; 2007b). Hilborn (2007b) noted that from the $1990 \mathrm{~s}$, marine ecologists had published many papers in highly-regarded journals such as Nature and Science, claiming the significant decline in global fisheries.

The disagreement between ecologists and fisheries scientists regarding the global status of fisheries peaked in 2006 when 14 marine ecologists and economists led by Dr. Boris Worm (Dalhousie University, Canada) wrote a paper alluding to the prediction that global populations of wildcaught marine fish (finfish and invertebrates) will be $100 \%$ collapsed by 2048 (Worm et al., 2006). The paper was titled "Impacts of Biodiversity Loss on Ocean Ecosystem Services" and was published in Science journal which then attracted much attention from the public as well as controversies among scientists.

The prediction of fisheries' global collapse by 2048 was one among many works stemming from ecologists' views on the status of global fisheries. Boris Worm had frequently got involved in writing such a topic, for example in Myers \& Worm (2003) and Baum et al. (2003). One paper from other ecologists had once hinted at the possibility of global fisheries collapse (i.e., 
Pauly et al., 1998). However, the Worm et al. (2006) paper was the first to predict the collapse in a specific year, 2048.

The method used to derive the 2048 projection was actually simple. Worm et al. (2006) used FAO's time series data on global catches of fish consisting of marine finfish, crustaceans, and molluscs. One important assumption was made, i.e., catch data was a proper proxy of abundances of fish populations. Accordingly, when the amount of catch declines, the associated population also declines. Later on, the criterion of collapsed populations was determined as the condition in which a population dropped to less than $10 \%$ of its maximum abundance as reflected by catch less than $10 \%$ of the highest catch ever recorded (Worm et al., 2006). With this definition of collapse, it was identified that the number of collapsed populations has been increasing over time. This increasing collapse data was then analyzed using regression and extrapolated to obtain the time when the $100 \%$ collapse occurs (Figure 1). From this extrapolation, they got the year 2048 .

This essay reviews the controversies occurring after the publication of the Worm et al. (2006) paper. The weaknesses in the analysis leading to the 2048 projection are also briefly discussed. Ultimately, this essay makes a conclusion regarding the validity/invalidity of the claim that fish will disappear by 2048 .

\section{CONTROVERSIES ON THE 2048 PROJECTION}

The 2048 projection, as mentioned in Worm et al. (2006) became sensational. However, in the original paper, the projection was not a big part, rather as stated by Stokstad (2009), only as the side note of the entire paper. Bigger attention on this issue arose when Boris Worm brought their prediction to the press release (Branch, 2008; Stokstad, 2009; Branch, 2013). After that, this issue was widely reported in the media around the world (Longhurst, 2007; Hilborn, 2007a; Branch, 2008), even hitting the front pages of world newspapers like the New York Times and Washington Post (Hilborn, 2015).

The issue then developed in the media, slightly deviated from what was reported in the original paper (i.e., Worm et al., 2006). In the Science paper, it was explained what may happen in 2048 is $100 \%$ collapse of global fisheries. But, this $100 \%$ collapse does not mean $100 \%$ of fish individuals being extinct in 2048, rather it means the abundances of all populations will drop to less than $10 \%$ of their maximum abundances. Therefore, when $100 \%$ collapse occurs, there will still be fish remaining. However, what appeared in the New York Times, Washington Post and National geographic were respectively "global collapse of fish species (Dean, 2006)", "world's fish supply running out (Eilperin, 2006)" or "seafood may be gone by 2048 (Roach, 2006)" without further definitions being given. The exaggerated headings in mass media, in turn, imposed the perception that all fish would be extinct in 2048, and this is what was incorrectly thought by the public.

As soon as the Worm et al. (2006) paper was published, it received opposition from many fisheries scientists. At least six papers were published simultaneously in Science Vol. 316 criticizing the Worm et al. paper in which three of those were in the form of technical comments (Holker et al., 2007; Jaenike, 2007; Wilberg \& Miller, 2007) and three others were in the form of 


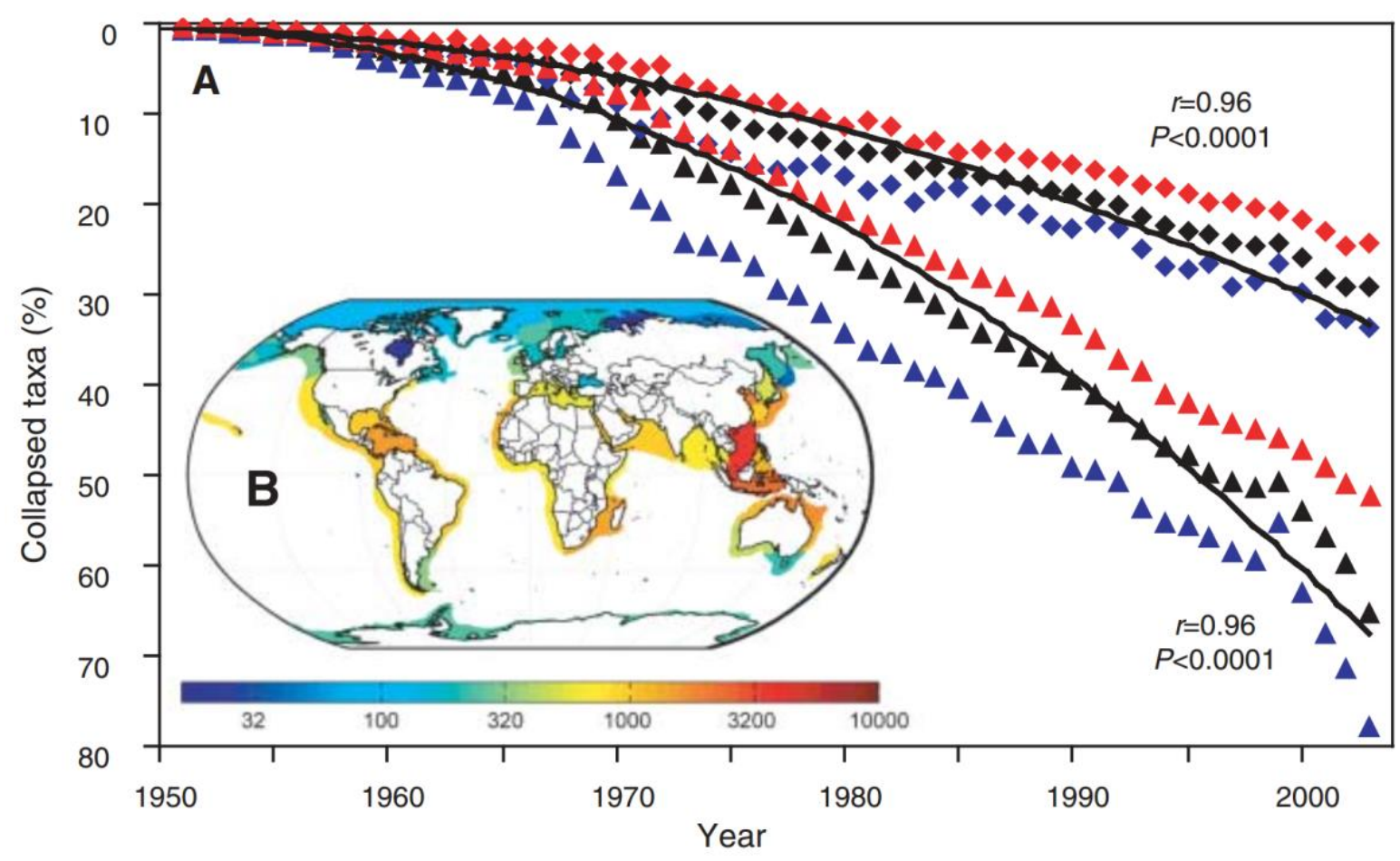

Figure 1. Original figure from Worm et al. (2006) describing trajectories of collapsed fish and invertebrates (diamonds, collapse by year; triangle, cumulative collapse) from which the projection of $100 \%$ collapse in 2048 was derived.

letters to the editor (Briggs; 2007; Murawski et al., 2007, Hilborn, 2007c).

A short communication was also published in the journal Marine Policy (i.e., Branch, 2008). Some of those only criticized the paper for its problematic analysis, others explicitly rebutted the projection. Further criticisms were written by Longhurst (2007), Hilborn (2007a; 2007b; 2007c) and Branch et al. (2011). Towards those technical comments and letters in Science, the Worm's team gave their response in the same journal (i.e., Worm et al., 2007a; Worm et al., 2007b). In response to Branch's short communication, another researcher wrote a counter article (i.e., Froese, 2009) which advocated the Worm et al. projection

There were some problems in the 2048 projection proposed by Worm et al. (2006) as uncovered by fisheries scientists. One of the problems was the extrapolation of the trend to the year 2048 using the dataset spanning only from 1950 to 2003 . This extrapolation was "too far beyond the existing data (Holker et al., 2007)". Another issue revealed by Holker et al. (2007) was the implicit assumption that the number of collapsed populations and time are directly related. In fact, we cannot know the trend of the number of collapsed fisheries after 2003. The assumption that the number of collapsed populations increases over time has no rationale.

Other authors revealed some more problems which are more statistically and mathematically technical in Worm et al. (2006). Wilberg \& Miller (2007), for example, criticized the use of time series analysis in the paper. From the statistics point of view, the increase in populations' collapses Worm et al. identified, may be due to the definition of collapse they set, rather than to the real decline (Wilberg \& 
Miller, 2007; Branch et al., 2011). Furthermore, Branch (2008) revealed major mathematical errors in the Worm et al. (2006) analysis. Based on his analysis, Branch was convinced that $100 \%$ collapse in one specific year cannot happen. In addition, Jaenike (2007) showed the evidence that future projection based on the regression model was highly unreliable. Another problem was on the interpretation of simple correlation in large scale study. Longhurst (2007) criticized Worm et al. for making an inference without knowing the mechanism underlying the correlation. The defense papers written by the Worm's team as well as Reiner Froese (i.e., Worm et al., 2007a; Worm et al., 2007b; Froese, 2009) could not deny those problems in the Worm et al. (2006) analysis.

One main weakness which fisheries scientists were commonly concerned about, was the basic assumption underlying the analysis towards the 2048 projection. As many previous ecologist's papers discussing global fisheries, Worm et al. (2006) assumed that the catch reflects abundance. Longhurst (2007), Murawski et al. (2007), Hilborn (2007b; 2007c), and Branch (2008) openly put forward their disagreements on this assumption. In reality, catch can be affected by many factors such as management policies that restrict catch, market forces, and even errors in catch reporting (Hilborn, 2007c; Branch, 2008; Branch, 2011). Hilborn $(2007 \mathrm{c})$ argued that in nature fish populations could fluctuate dramatically, and the low population was not necessarily the signal of depletion due to overexploitation. Also, from the perspective of Statistics, long time series data had a high chance to get fisheries collapsed if the Worm et al. criterion was followed. The George Bank haddock
(Murawski et al., 2007) and the fisheries in the Bering Sea (Hilborn, 2007b) are two examples in which catch data clearly do not represent abundance. If catch data from FAO is used, then both fisheries will be categorized as collapsed, which are definitely not the cases according to thorough researches on abundance (Murawski et al., 2007; Hilborn, 2007b). Furthermore, Branch et al. (2011) contrasted the catch and biomass data for showing the trend of 234 fish populations in the U.S. West Coast. They found that catch and biomass data analysis produce a significantly different proportion of collapsed fisheries, and no trend of the increasing number of the collapse was shown from biomass analysis.

Hilborn (2007c) argued that not all fisheries experienced overexploitation. He pointed out U.S., New Zealand, Iceland, and Australia as having successfully reduced overfishing. In another paper, he revealed the percentage of the overfished stocks in the U.S. as declining from $33 \%$ in 2001 to $26 \%$ in 2005 (Hilborn, 2007b). So, even if in many parts of the world fisheries are depleted as viewed by ecologists, it does not mean all fisheries are in the same conditions. Some are in good condition.

\section{WAR AND RECONCILIATION}

The opposition to the 2048 projection got increasingly intense. In a short communication, Branch (2008) stated explicitly that the 2048 projection of Worm et al. (2006) was "incorrect". Murawski et al. (2007) called it "inaccurate and overly pessimistic". "Hilborn et al. (2007c) rudely said that the projection was "fallacious and inappropriate to appear in a scientific journal". Even worse, in an interview with the CBC Radio-Canada, Ray Hilborn said 
that the 2048 projection is "just mindbogglingly stupid" (Burgess, 2014). Prof. Ray Hilborn is a fisheries scientist at The University of Washington, U.S., who voiced most loudly against the 2048 projection and other relating views on declining global fisheries. The opposition of Ray Hilborn to Boris Worm had started before the Worm et al. (2006) paper was published. In 2003, Worm coauthored an article in Nature, suggesting the biomass of large predatory fish has dropped to $10 \%$ (Myers \& Worm, 2003). Hilborn criticized the paper in 2006 (i.e., Hilborn, 2006).

Oppositions of fisheries scientists (in particular Ray Hiborn) to Worm et al. (2006) paper provoked other marine ecologists to react. Prof. Daniel Pauly from The University of British Columbia, a prominent fisheries ecologist who was known to lead the view on declining global fisheries, accused fisheries scientists of having conflicts of interest with fishing industries because some of their researches were funded by them (Pauly, 2009; Burgess, 2014). The attacks to Ray Hilborn were supported by some NGOs such as Greenpeace. Greenpeace accused Hilborn of not disclosing properly the funding sources he received for his studies. Greenpeace even labeled Hilborn as "the overfishing denier" (Hocevar, 2016). Hiborn defended himself against those charges in his personal blog.

Surprisingly, after three years of intense "conflict", in 2009 Boris Worm and Ray Hilborn came to reconciliation (Stokstad, 2009; Burgess, 2014). Using new better datasets, they decided to collaborate analyzing global fisheries, resulting in a joint paper. This paper (i.e., Worm et al., 2009) was published in Science involving 21 authors from both ecologists and fisheries scientist sides. The paper discussed the current status of global populations and ecosystems, which were grouped into some categories: stable, declining, collapsed, and rebuilding. The article concluded that fisheries management in some regions have succeeded in reducing overexploitation, and the same management efforts need to be enforced in other regions to reverse the collapsed condition. Another joint paper followed up in 2012, published in the journal Trends in Ecology \& Evolution, resulted from a collaboration between Boris Worm and Trevor Branch (another fisheries scientist from the University of Washington who strongly opposes the 2048 projection) (i.e., Worm \& Branch, 2012). This paper argues that the state and future of fisheries are different from one region to another even though it is admitted some regions really need immediate actions for management and conservation. For the side of Boris Worm and other ecologists, these two papers indirectly rectified the $100 \%$ collapse projection in 2048, as previously claimed in the Worm et al. (2006) paper.

However, not all ecologists were willing to be reconciled with fisheries scientists. Daniel Pauly and colleagues are the ecologists who keep insisting on utilizing catch data as the proxy for fish abundance (e.g., Froese et al., 2012; Pauly, 2013). They are consistently suggesting that the global fish populations are being depleted as reflected in their publications (e.g., Zeller et al., 2009; Watson et al., 2013; Watson \& Pauly, 2013). As a result, the debates between the groups of marine ecologists and fisheries scientists have not come to an end and are unlikely to in the near future. 


\section{CONCLUSIONS}

It has been shown that marine ecologists and fisheries scientists have different views concerning whether or not global fisheries are declining. The debate on the status of global fisheries is still going on. However, the prediction of the fish disappearance by 2048, as reported in the media, has been argued to be incorrect. Firstly, the $100 \%$ collapse as originally mentioned in the Worm et al. (2006) paper does not mean that all fish individuals will be gone, whereas $100 \%$ of fish populations decrease to the level less than $10 \%$ of its highest abundances. Even if the projection is correct, there will still be fish left in the ocean. Secondly, there were many problems in the analysis that led to the 2048 projections. More importantly, the basic assumption used in the analysis has been disproven in some regions. So, the projection is unlikely to be true. Thirdly, the authors who proposed the 2048 projection actually had rectified the projection. While the future remains uncertain, the existing studies and data do not support the premature conclusion of global fisheries collapse. Therefore, there is no reason to keep insisting on the claim that fish will disappear by 2048 . For the future, some precautions should be taken in using catch statistics as well as long-term projections to infer about the status of fish populations. Catch statistics are indeed important, however, to assess the population status, it needs to be combined with other available fisheries data. Furthermore, researchers must be careful in communicating a potentially controversial result to the public because it is easily misinterpreted and may trigger unnecessarily fear and pessimism.

\section{REMARKS}

This paper was developed from the author's assignment in the Pre-Departure Training (PDT) of Australia Awards Scholarship. Gratitude was conveyed to the PDT instructor, Alana Tailby, for useful correction in the original manuscript and encouraging the author to publish it.

\section{REFERENCES}

Baum, J. K., Myers, R. A., Kehler, D. G., Worm, B., Harley, S. J., Doherty, P. A. (2003). Collapse and conservation of shark populations in the Northwest Atlantic. Science, 299: 389-392.

Branch, T. A. (2008). Not all fisheries will be collapsed in 2048. Marine Policy, 32: 38-39.

Branch, T. A. (2013). Citation patterns of a controversial and high-impact paper: Worm et al. (2006) "Impacts of biodiversity loss on ocean ecosystem services". PloS ONE, 8(2): e56723.

Branch, T. A., Jensen, O. P., Ricard, D., Ye, Y., Hilborn, R. (2011). Contrasting global trends in marine fishery status obtained from catches and from stock assessments. Conservation Biology, 25: 777-786.

Briggs, J. C. (2007). Biodiversity loss in the ocean: How bad is it?. Science, 316, 1282 .

Burgess, M. (2014). Case study: The Hilborn-Worm debate on the status of global fisheries (online). Retrieved from https://theteteatete.org/2014/12/ 03/case-study-the-hilborn-wormdebate-on-the-status-of-globalfisheries on October 20, 2016.

Dean, C. (2006). Study sees 'Global collapse' of fish species (online). Retrieved from http://www.nytimes. 
com/2006/11/03/science/03fish.html on October 20, 2016.

Eilperin, J. (2006). World's fish supply running out, researchers warn (online). Retrieved from http://www. washingtonpost.com/wpdyn/content/ article/2006/11/02/AR20061102009 13.html on October 20, 2016.

Froese, R. (2009). Out of new stocks in 2020: A comment on "Not all fisheries will be collapsed in 2048". Marine Policy, 33: 180-181.

Froese, R., Zeller, D., Kleisner, K., \& Pauly, D. (2012). What catch data can tell us about the status of global fisheries. Marine Biology, 159: 1283-1292.

Hilborn, R (2006). Faith-based fisheries. Fisheries, 31: 554-555.

Hilborn, R. (2007a). Moving to sustainability by learning from successful fisheries. AMBIO: $A$ Journal of the Human Environment, 36(4): 296-303.

Hilborn, R. (2007b). Reinterpreting the state of fisheries and their management. Ecosystems, 10: 13621369.

Hilborn, R. (2007c). Biodiversity loss in the ocean: How bad is it?. Science, 316: 1281-1282.

Hilborn, R. (2015). Why do some bogus stories never die? All fish stocks collapsed by 2048. Retrieved from https://rayhblog.files.wordpress.com/ 2015/05/why-do-some-bogusstories-never -die.pdf on October 6, 2016.

Hocevar, J. (2016). Ray Hilborn: Overfishing denier. Retrieved from http://www.greenpeace.org/usa/ research/overfishing-denier/ on October 6, 2016.
Holker, F., Beare, D., Dorner, H., di Natale, A., Ratz, H-J., Temming, A., Casey. J. (2007). Comments on "Impacts of biodiversity loss on ocean ecosystem services". Science, 316: 1285c.

Jaenike, J. (2007). Comments on "Impacts of biodiversity loss on ocean ecosystem services". Science, 316: $1285 \mathrm{a}$.

Kleisner, K., Zeller, D., Froese, R. \& Pauly, D. (2013). Using global catch data for inferences on the world's marine fisheries. Fish and Fisheries, 14(3): 293-311.

Longhurst, A. (2007). Doubt and certainty in fishery science: Are we really headed for a global collapse of stocks?. Fisheries Research, 86: 1-5. Murawski, S. A., Methot, R., Tromble, G. (2007). Biodiversity loss in the ocean: how bad is it?. Science, 316 : 1281.

Myers, R. A., Worm, B. (2003). Rapid worldwide depletion of predatory fish communities. Nature, 423: 280-283.

Pauly, D. (2009). The end of fish. Retrieved from https://newrepublic.com/article/ 69712/ aquacalypse-now. on October 20, 2016.

Pauly, D. (2013). Does catch reflect abundance? Yes, it is a crucial signal. Nature, 494: 303-306.

Pauly, D., Christensen, V., Dalsgaard, J., Froese, R., Torres Jr., F. (1998). Fishing down marine food webs. Science, 279: 860-863.

Roach, J. (2006). Seafood may be gone by 2048, study says. Retrieved from http://news.nationalgeographic.com/ news/2006/11/061102-seafoodthreat.html. on October 20, 2016.

Stokstad, E. (2009). Detente in the fisheries war. Science, 324: 170-171. 
Watson, R. A., Cheung, W. W. L., Anticamara, J. A., Sumaila, U. R., Zeller, D., Pauly, D. (2013). Global marine yield halved as fishing intensity redoubles. Fish and Fisheries, 14: 493-503.

Watson, R. A., Pauly, D. (2013). The changing face of global fisheries The 1950s vs. the 2000s. Marine Policy, 42: 1-4.

Wilberg, M. J., Miller, T. J. (2007). Comments on "Impacts of biodiversity loss on ocean ecosystem services". Science, 316: 1285b.

Worm, B., Barbier, E. B., Beaumont, N., Duffy, J. E., Folke, C., Halpern, B. S., Jackson, J. B. C., Lotze, H. K., Micheli, F., Palumbi, S. R., Sala, E., Selkoe, K. A., Stachowicz, J. J., Watson, R. (2006). Impacts of biodiversity loss on ocean ecosystem services. Science, 314: 787-790.

Worm, B., Barbier, E. B., Beaumont, N., Duffy, J. E., Folke, C., Halpern, B. S., Jackson, J. B. C., Lotze, H. K., Micheli, F., Palumbi, S. R., Sala, E., Selkoe, K. A., Stachowicz, J. J., Watson, R. (2007a). Response to comments on "Impacts of biodiversity loss on ocean ecosystem services". Science, 316: 1285d.
Worm, B., Barbier, E. B., Beaumont, N., Duffy, J. E., Folke, C., Halpern, B. S., Jackson, J. B. C., Lotze, H. K., Micheli, F., Palumbi, S. R., Sala, E., Selkoe, K. A., Stachowicz, J. J., Watson, R. (2007b). Response to "Biodiversity loss in the ocean. How bad is it?". Science, 316: 1282-1284.

Worm, B., Branch, T.A. (2012). The future of fish. Trends in Ecology \& Evolution, 27: 594-599.

Worm, B., Hilborn, R., Baum, J. K., Branch, T. A., Collie, J. S., Costello, C., Fogarty, M. J., Fulton, E. A., Hutchings, J. A., Jennings, S., Jensen, O. P., Lotze, H. K., Mace, P. M., McClanahan, T. R., Minto, C., Palumbi, S. R., Parma, A. M., Ricard, D., Rosenberg, A. A., Watson, R., Zeller, D. (2009). Rebuilding global fisheries. Science, 325: 578-585.

Zeller, D., Cheung, W., Close, C., Pauly, D. (2009). Trends in global marine fisheries, a critical view. In Wrammer, P., Ackefors, H., Cullberg, M. (eds). Fisheries, trade and development (pp. 87-107). Royal Swedish Academy of Agriculture and Forestry, Stockholm. 